\title{
Analisis Dekonstruktif Terhadap Satira Sosiobudaya dan Politik dalam Filem Lelaki Harapan Dunia (2014)
}

\author{
BADRUL REDZUAN ABU HASSAN \\ NUR HAFIZOH IDRIS \\ Universiti Kebangsaan Malaysia
}

\begin{abstract}
ABSTRAK
Satira merupakan suatu reaksi komunikatif yang dihasilkan dan digunakan oleh sesiapa yang mempunyai keupayaan retorik untuk mengkomunikasikan saranan, sindiran atau pandangan peribadi atau kolektif. Masyarakat Melayu di Nusantara Melayu memiliki kecenderungan bersatira sebagai sebahagian dari akal budi Melayu yang menonjolkan kehebatan warisan bahasa untuk tujuan menegur, mendidik dan memperbaiki akhlak sejajar dengan ajaran agama Islam. Satira dinikmati secara mapan pada hari ini sebagai representasi kehidupan seharian yang dihasilkan untuk tujuan hiburan dan seloka persendaan. Komunikasi bersatira dilihat semakin popular dan digunapakai oleh sebilangan masyarakat era digital yang giat menyuarakan pendapat serta kritikan mereka terutamanya melibatkan persoalan logik, agama, moralitas dan integrit pemimpin masyarakat dan figura popular. Dalam erti kata lain, aspek sosiobudaya dan politik dilihat mendominasi wacana bersatira yang berlangsung di ruang publik termasuklah menerusi budaya popular seperti filem. Makalah ini umumnya bertujuan mengupas dan membahas menerusi sebuah analisis dekonstruktif aliran Derrida untuk menemukan makna-makna yang tersulam dalam wacana bersatira filem Lelaki Harapan Dunia $(L H D, 2014)$ arahan Liew Seng Tat. Melalui kaedah analisis dekonstruktif, hasil kajian menunjukkan terdapat satira yang mewacanakan aspek sosiobudaya dan politik dalam filem ini. Persendaan satira sosiobudaya menumpukan implikasi dan subteks wacana kepada permasalahan penggunaan bahasa Malaysia dan ketaksuban masyarakat terhadap alam metafizik, sedangkan persendaan satira politik menjurus kepada amalan sogokan oleh ahli politik korup. Rumusan pencerahan yang ditemukan dari analisis dapatan kajian mencadangkan bahawa pengarah filem ini telah membuat representasi yang klinikal dan kritis mengenai akal budi Melayu dengan strategik dan menarik menerusi satira sosiobudaya dan politik.
\end{abstract}

Kata kunci: Akal budi Melayu, satira sosiobudaya, satira politik, analisis dekonstruktif, metafizik.

\section{A Deconstructive Analysis of Sociocultural and Political Satire in Lelaki Harapan Dunia (2014)}

\begin{abstract}
A satire is a form of communicative reaction that is often the result of one's rhetorical ability to construct and deploy it for the purpose of giving advice, sarcasm, one's personal opinion or a collective point of view on a specific issue. Malay communities in the Malay Archipelago have been known as the interlocutors of satirical discourse as it has always been derived as part of Malay wisdom and the versatile heritage of the Malay language as a social tool to give advice, teach, and improve mannerism in accordance with the Islamic values. A satire is typically consumed today as a socially-situated everyday representation which serves the general purpose of pleasure and light-hearted amusement. Satirically communicated opinions and criticisms pertaining to the subject of religion, morality and integrity of public figures have risen in popularity among members of the digital society. In other words, socio-cultural and political aspects have since been the dominant discourses in the public sphere including through film as popular culture. This paper aims to explore and discuss through the
\end{abstract}


Derridean deconstructive analysis the meanings embedded in the satirical film Lelaki Harapan Dunia (LHD, 2014), directed by Liew Seng Tat. The findings point out that the satirical practice in the film is invariably linked to socio-cultural and political discourses. Upon deconstruction, the sociocultural satires are deemed to be implicating the complicated maintenance of standard usage of Bahasa Malaysia, and the overwhelming fixation of Malay villagers with 'Malay' metaphysics, on the one hand; whereas the political satire is focussed on the practice of bribery by a corrupt politician, on the other. In the final analysis, the study's findings seem to have brought light upon a clinical and critical representation of Malay wisdom with strategic and interesting socio-cultural and political satires.

Keywords: Malay wisdom, socio-cultural satire, political satire, deconstructive analysis, metaphysics.

\section{PENDAHULUAN}

Satira merupakan suatu reaksi komunikatif yang dihasilkan dan digunakan oleh sesiapa yang mempunyai keupayaan retorik untuk mengkomunikasikan saranan, sindiran atau pandangan peribadi atau kolektif terhadap tingkah laku atau fenomena yang telah menyebabkan ia menjadi isu dan tumpuan di ruang publik. Bersatira memerlukan tujuan dan kesan komunikatif yang jelas untuk menarik perhatian khalayak sasaran, masyarakat mengenai persoalan yang ingin dieksploitasi dan dimanipulasi. Masyarakat Melayu di Nusantara Melayu memiliki kecenderungan bersatira sebagai sebahagian dari akal budi Melayu yang menonjolkan kehebatan warisan dan kiasan bahasa seperti metafora dan simbolisme untuk tujuan menegur, mendidik dan memperbaiki akhlak sejajar dengan ajaran agama Islam. Kemajuan teknologi komunikasi menyebabkan satira lisan bertransformasi kepada imej atau visualisasi bersemiotik seperti yang diupayakan oleh filem. Menerusi sinema dan media penyiaran amnya, pada hari ini satira dapat dinikmati oleh pelbagai kalangan etnik dan kelas sosial sebagai representasi kehidupan seharian dan ia dihasilkan untuk tujuan hiburan secara mapan, terutama bagi tujuan komersil yang penting untuk menentukan rantaian penyediaan dan permintaan 'hiburan' atau 'persendaan' tidak terputus.

Di sisi lain, kecenderungan terhadap elemen retorik dilihat terus dipupuk dalam masyarakat negara ini sebagai wadah dan kaedah komunikasi 'alternatif' di kalangan pemikir, pembikin filem dan golongan intelektual amnya. Komunikasi bersatira dilihat semakin popular dan digunapakai oleh sebilangan masyarakat era digital yang giat menyuarakan pendapat serta kritikan mereka terutamanya melibatkan persoalan logik, agama, moralitas dan integriti pemimpin masyarakat dan figura popular. Dalam ertikata lain, aspek sosiobudaya dan politik dilihat mendominasi wacana bersatira yang berlangsung di ruang publik bukan sahaja menerusi platform media sosial, tetapi juga menerusi sinema yang mampu mengangkat representasi sosiobudaya dan politik dengan lebih realistik, mantap, bernuansa dan holistik. Ini dapat menggambarkan juga bahawa para intelektual, budayawan dan penggiat industri kreatif sentiasa mengikuti perkembangan semasa sosiobudaya dan politik khususnya yang melibatkan masyarakat Melayu Islam di negara ini. Justeru, makalah ini umumnya akan mengupas dan membahas menerusi sebuah analisis dekonstruktif aspek satira sosiobudaya dan politik yamg tersulam dalam wacana bersatira filem Lelaki Harapan Dunia (LHD, 2014) arahan Liew Seng Tat.

\section{Peradaban, Falsafah dan Bahasa Melayu}

\section{SOROTAN LITERATUR}

Sesebuah peradaban bangsa wujud bersama bahasa kerana kedua-duanya bersifat saling melengkapi antara satu sama lain. Peradaban Melayu telah meninggalkan warisan khazanah budaya yang sangat banyak terhadap perkembangan budaya dan bahasa pada masa kini (A. 
Aziz Deraman, 2000). Peradaban Melayu wujud dalam Alam Melayu dan secara zahirnya Alam Melayu merangkumi gugusan pulau-pulau serta Semenanjung Tanah Melayu yang didiami oleh Rumpun Bangsa Melayu semenjak zaman berzaman. Kepulauan ini dan lautan serta selat di antaranya juga dikenali sebagai Nusantara (Nusa-antara-lautan). Nusantara atau Alam Melayu wujud sebelum penubuhan Malaysia, Singapura, Brunei, Filipina dan Republik Indonesia. Sejarah rantau Asia boleh dibahagikan kepada zaman purba atau pra sejarah, zaman kerajaan Hindu Budha, zaman kerajaan Islam dan akhirnya zaman kolonial. Selepas zaman kolonial, Nusantara berpecah kepada beberapa negara iaitu Brunei, Filipina, Indonesia, Malaysia, Singapura dan Timor Timur. Inilah yang dikatakan sebagai Nusantara dan merupakan tanah air bagi Rumpun Bangsa Melayu yang berkongsi satu baka keturunan, adatresam, bahasa dan budaya. Menurut Abdul Rahman Embong (1999), budaya Melayu pada dasarnya adalah budaya yang amat menuntut kepada kehalusan dan adab dalam semua tatacara kehidupannya. Menurut Asmah (1992) dlm. Noor Hasnoor et al. (2019, hlm.371), terdapat empat kaedah yang digunakan oleh orang Melayu untuk menyampaikan sesuatu perkara yang menunjukkan pentingnya nilai kesopanan komunikasi dalam masyarakat Melayu, iaitu "bahasa berlapik, iaitu serkap jarang (beating about the bush), kiasan (imagery), berbalik (contradicting), dan orang perantaraan (surrogate)". Kehalusan dan adab inilah yang membentuk etos kemelayuan yang sering menjadikan bangsa Melayu sebagai bangsa yang berpekerti mulia, prihatin dan mementingkan keharmonian. Etos ini diterapkan dalam semua aktiviti budaya bangsa Melayu, termasuk bahasa dan seninya hingga membentuk satu model tingkah laku unggul dan diwarisi dari generasi ke generasi.

Masyarakat Melayu tradisional yang terkenal dengan sifat sopan santun telah membuatkan mereka mencari alternatif lain untuk mengkritik golongan bangsawan dan pemerintah secara halus. Sikap masyarakat Melayu yang tidak berterus terang, sentiasa melapik kata, menyampir makna dalam menyampaikan kritikan ini akhirnya membentuk bahasa kiasan, ibarat dan perumpamaan yang dijadikan sandaran untuk bangsa Melayu. Dari sinilah terbentuknya pengungkapan orang Melayu, 'Ular dipukul biar mati, kayu pemukul jangan patah' dengan tujuan menyampaikan makna bahawa sasaran biar mengena, kaedah biar sempurna supaya yang ditujukan jangan sampai tercela. Begitulah indah dan halusnya budaya bangsa Melayu yang telah dipupuk sejak zaman berzaman (Asmah, 1986).

\section{Epistemologi Satira}

Menurut sejarah, satira wujud bagi memenuhi keperluan pengkarya bagi menyatakan ketidakpuasan hati mereka terhadap sesuatu perkara seperti yang dipentaskan dalam teater terdahulu. Menurut Asmah (1986), semasa zaman klasik persembahan satira disampaikan secara spontan di atas pentas dan mempunyai sedikit persamaan dengan konsep yang diterapkan dalam persembahan dikir barat di Malaysia. Satira merupakan cabang dalam bidang kesusasteraan dan lazimnya dipersembahkan sebagai karya yang bersifat lucu tetapi hakikatnya ia sarat dengan unsur-unsur lain seperti sindiran dan kritikan. Menurut Fatimah (1992), satira adalah sesuatu ekspresi berbentuk kritikan halus terhadap penyalahgunaan kuasa, penindasan, masalah sosial masyarakat, kepimpinan yang jahat dan adat resam yang salah.

Konsep satira mula dipelopori oleh penyair dan pengarang Greek termasuklah Aeschylus, Sophocles, Euripides, Homer dan Virgil (satira berunsur tragedi) dan Aristophanes (komedi), banyak menghasilkan karya yang menjadi inspirasi kepada pengkarya lain (Fatimah, 1992). Para penyair dan pengarang Rom seperti Horace, Juvenal dan Lucilius menggunakan 
unsur satira dalam puisi Latin mereka untuk memberi sumpahan kepada musuh dan disampaikan dalam bentuk pemujaan kepada dewa-dewa untuk memohon pertolongan dan dilaksanakan dalam bentuk ritual tertentu yang lazimnya mempunyai hubungan dengan unsur-unsur seperti pemusnahan dan kematian kepada pihak yang menjadi mangsa atau yang memulakan sengketa. la mempunyai unsur-unsur sihir yang menggunakan kuasa ghaib untuk membalas dendam terhadap individu tertentu (Griffin, 2015).

Menurut Koko (2016), satira dalam kesusasteraan moden menggunakan pendekatan yang lebih agresif. Ini dapat dilihat dalam puisi Don Juan karya Lord Byron yang menyindir tingkah laku manusia yang hanya mengikut hawa nafsu dan Joseph Conrad menerusi novel pasca kolonialnya seperti Heart of Darkness dan Almayer's Folly yang mengisahkan tentang bangsa Eropah, Afrika dan Asia yang sentiasa dahagakan kekayaan dan bertuhankan nafsu. Satira digunakan untuk menyindir kuasa-kuasa politik yang mempunyai ideologi terkuat di dunia seperti Amerika dan Rusia sebagaimana yang terdapat dalam novel Animal Farm tulisan George Orwell. Hampir keseluruhan karya berunsur satira pada peringkat awal kurun ke-20 disampaikan akibat daripada keadaan kebingungan dan kekeliruan masyarakat dalam menghadapi kehidupan. la dapat dilihat dengan jelas dalam drama Waiting for Godot yang merupakan rintihan masyarakat atas kemusnahan dan penderitaan mereka selepas perang dunia pertama. Masyarakat mula mempersoalkan kekuasaan tuhan dan institusi keagamaan kerana tidak dapat menerima realiti selepas peperangan dan ia dipersembahkan dalam persembahan satira.

\section{Satira dalam Budaya Popular Malaysia}

Majalah MAD yang pernah diterbitkan di Amerika Syarikat semasa era 1970an telah mempengaruhi pengkarya kartun dari Malaysia untuk menerbitkan majalah humor yang setanding MAD. Pada tahun 1978, majalah Gila-Gila yang diinspirasikan oleh majalah MAD telah diterbitkan dan ia mengambil pendekatan yang sama seperti MAD tetapi diolah mengikut identiti Malaysia dan berjiwa tempatan. Majalah Gila-gila mendapat sambutan luar biasa apabila cetakan pertamanya yang berjumlah 10,000 naskhah habis dijual dan mendapat sambutan luar biasa. Kartun-kartun yang disiarkan dalam majalah Gila-gila sarat dengan mesej yang simbolik dan menggunakan tagline 'Majalah Humor Nasional'.

Penggunaan satira dapat dilihat dalam kata-kata masyarakat Melayu seperti tegur, timbang, nilai, pandangan, pendapat, ulas, ukur, kias, sindir dan taksir. Satira juga boleh ditemui dalam ungkapan peribahasa, bidalan, perumpamaan dan puisi tradisional. Satira dalam kesusasteraan Melayu Klasik telah muncul di Nusantara melalui kiasan-kiasan yang terdapat dalam folklore atau cerita rakyat yang bermotif haiwan dan cerita-cerita jenaka seperti Pak Kadok, Lebai Malang, Musang Berjanggut, Si Luncai dan Sang Kancil. Cerita-cerita ini disampaikan daripada satu generasi ke satu generasi sebagai pengajaran dan pedoman hidup. Satira dan budaya Melayu seperti sudah sebati kerana komunikasi harian bangsa Melayu telah lama menggunakan gaya bahasa satira bagi menyindir atau menegur seseorang secara berlapik. Pada hari ini, masyarakat digital tidak lagi menggunakan folklore untuk mengkonstruksi satira tetapi mereka memilih khususnya media digital yang mempunyai pelbagai aplikasi dan platform media sosial untuk membangunkan apa yang disebut sebagai 'meme' atau seloka persendaan. Menurut pengkaji media sosial, Faizul Nizar et al. (2018, hlm.81), penggunaan 'meme' dapat mempersendakan seseorang dengan cara yang halus termasuk golongan bangsawan, kenamaan dan pelbagai organisasi mahupun institusi kerajaan dan hal ini sebenarnya dapat pula "memberi kesan mendalam" kepada "mangsa". Kajian Raja Nurafiqah et al. (2019) pula mengemukakan istilah 'troll' yang bermaksud suatu 
provokasi yang disengajakan untuk menarik perhatian seseorang individu atau kolektif sehingga menular menerusi Internet. Seperti sudah menjadi 'tradisi', golongan ahli politik, bangsawan dan hartawan akan menjadi sasaran satira atau 'trolling' politik bagi maksud mengkomunikasikan pandangan politik masing-masing, "suka dan juga benci" (225).

Satira juga seringkali digunakan oleh pengkarya filem seperti Tan Sri P. Ramlee dan hal ini dapat dilihat dalam filem Bujang Lapok (1957), Nujum Pak Belalang (1959), Musang Berjanggut (1959), Pendekar Bujang Lapok (1959) dan banyak lagi. Kebanyakan filem beliau menggunakan medium satira yang disampaikan melalui komedi. Tan Sri P. Ramlee telah membentangkan realiti kehidupan selepas kemerdekaan yang sukar namun sarat dengan kasih sayang, belas kasihan dan harapan yang digarap dengan kemas dalam bentuk humor. Ruang-ruang satira yang ditinggalkan oleh P. Ramlee kemudiannya diisi oleh pengarahpengarah lain dalam bentuk teater, sitkom, drama dan filem seperti karya Hassan Muthalib, Dinsman, Al-Jafree, Sabri Yunus, Mamat Khalid, Othman Hafsham, dan A.R. Badul.

Kini, satira menjadi satu fenomena dan banyak rancangan televisyen yang menggunakan satira sebagai asas kepada penerbitan sesebuah program. Antara program yang mengandungi satira ialah segmen parodi dalam Meletop, Maharaja Lawak, Sitkom Pi Mai Pi Mai Tang Tu, Buletin Cinta, Jenaka Kampung Kalut, Maharaja Lawak, Juara Parodi dan banyak lagi. Satira juga mengambil tempat dalam pembikinan drama dan filem di Malaysia. Antara filem yang sarat dengan satira ialah filem Dari Jemapoh ke Manchester, Gedebe, Nasi Lemak 2.0, Ola Bola, Man Laksa, Zombi Kampung Pisang dan banyak lagi. Filem sekuel Hantu Kak Limah contohnya mendapat sambutan yang amat menggalakkan dan dikatakan sebagai filem satira paling berpengaruh pada masa kini dengan jumlah kutipan 'pecah panggung'.

\section{METODOLOGI}

\section{Analisis Dekonstruktif}

Pendekatan interpretif yang dipilih dalam makalah ini ialah analisis tekstual aliran dekonstruktif atau dekonstruksi yang dikemukakan oleh ahli falsafah pascastrukturalisme, Jacques Derrida. Premis utama dekonstruksi Derrida ialah 'differance, iaitu sebuah kalimat dalam bahasa Perancis yang membawa dua makna penting kepada falsafah dekonstruksi Derrida. Pertama, ia bermaksud penundaan atau 'deference' makna. Kedua, ia juga bermaksud perbezaan atau 'difference' makna. Gabungan kedua-duanya akan menjadikan proses penemuan dan interpretasi sesuatu makna dalam kehidupan, khasnya konteks sosiobudaya dan politik, menjadi tidak tuntas serta tidak stabil kerana setiap makna itu akan ditunda serta berbeza-beza. Hal ini menjadi ciri utama pascastrukturalisme yang memanafaatkan teori dekonstruksi Derrida. Premis kedua dekonstruksi ialah untuk mengemukakan pertanyaan, perlawanan, perundingan serta pertanyaan ulang ke atas naratif dan konstruk sosiobudaya dan politik yang 'logosentrik' atau dianggap absah, mutlak dan dwinilai atau 'binary'. Analisis dekonstruksi dapat memusatkan permasalahan (baca permainan) 'penundaan dan perbezaan makna' yang tersulam dan terbina dalam budaya popular seperti filem yang berkonsepkan satira. 'Permainan' dekonstruktif tidak membenarkan suatu makna yang dimuktamadkan tetapi membenarkan makna, perspektif dan isu yang pluralistik dibaca bersama filem tersebut. Justeru, kami hanya menawarkan sebuah interpretasi wacana kritis dalam makalah ini mengenai fungsionalisme satira dalam filem LHD.

Analisis dekonstruktif atau dekonstruksi diterapkan ke atas bingkai atau frame pegun terpilih yang sarat dengan elemen-elemen simbolik: kami sedia maklum terdapat filem-filem Malaysia yang cenderung menjadikan konteks sosiobudaya dan politik negara sebagai latar 
belakang naratif LHD. Justeru, menerusi pembacaan semiotik berlapis menerusi analisis dekonstruksi makna denotatif dan kemudian makna konotatif (Badrul Redzuan, 2018), kami mendapati bahawa secara keseluruhannya, LHD telah dikonstruksikan sebagai filem komedi yang ingin mensatirakan realiti sosiobudaya dan politik kontemporari yang disandiwarakan menerusi perspektif sebuah masyarakat Melayu di sebuah desa yang menjunjung tradisi 'tamu agung' tetapi mempunyai pengetahuan literalis dan pengalaman yang terbatas dan tidak pragmatis dalam penyelesaian masalah atau konflik yang dihadapi oleh masyarakat desa mereka.

\section{Sinopsis filem Lelaki Harapan Dunia}

LHD berkisarkan reaksi sebuah masyarakat Melayu di sebuah desa sebelum dan semasa dilanda 'konflik'. Konflik bermula apabila Pak Awang mahu menghadiahkan sebuah rumah kepada anak perempuannya yang akan berkahwin. Rumah tersebut terletak jauh di dalam hutan dan perlu dipindahkan ke kawasan kampung terlebih dahulu sebelum proses pemulihan. Bagi merealisasikan impian tersebut, Pak Awang meminta bantuan penduduk kampung untuk memindahkan rumah tersebut ke perkampungan mereka. Semasa proses pemindahan, orang kampung dikejutkan dengan kehadiran orang hitam di dalam rumah tersebut. Penduduk kampung menjadi panik apabila beberapa kejadian aneh berlaku di kampung mereka dan mengaitkannya dengan penemuan 'orang hitam' yang dikatakan sebagai "Orang Minyak" di dalam rumah tersebut. Mereka menggunakan pelbagai cara untuk menangkap “Orang Minyak" dan situasi ini menimbulkan kekecohan di seluruh kampung.

\section{DAPATAN DAN ANALISIS}

\section{Satira Sosiobudaya}

i. 'Bahasa Jiwa Bangsa'

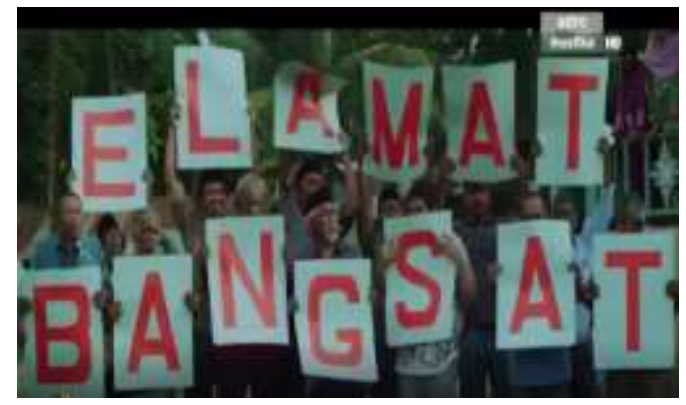

Rajah 1: 'Elamat Bangsat'

Rajah 1 di atas menunjukkan placard yang dipegang oleh penduduk kampung bagi mengalu-alukan kehadiran En. Juta Seri ke majlis 'Derma Unta' yang diadakan di Masjid Kubah Baru. Bagaimanapun ejaan 'Selamat Datang' yang sepatutnya tertera telah disusun secara salah sehingga terjadinya frasa 'Elamat Bangsat' yang tidak mempunyai apa-apa makna. Kesalahan ejaan yang dilakukan oleh orang kampung ini, sama ada secara sengaja atau tidak disengajakan ini kelihatan lucu dan membingungkan. la juga kedengaran amat sinikal kerana perkataan bangsat dalam aluan merupakan sebuah kata makian untuk merendahkan maruah seseorang. 
Menurut Yusri Abdul Malek dan Noor Jaafar (2005), 'bangsat' bermaksud seseorang yang sangat jahat perangainya dan merupakan sebuah kata makian untuk menghina seseorang dengan dahsyat sekali, merendahkan martabat serta melemahkan semangatnya. Dalam filem LHD, ahli politik kampung iaitu Tok Ketua dipotretkan sebagai seorang yang pecah amanah dan menggunakan duit 'Derma Unta' untuk tujuan tertentu yang dirahsiakan daripada pengetahuan orang kampung. Manakala En. Juta Seri pula sebagai wakil Persatuan Pemuda Bersatu (PBB) yang menggunakan kedudukannya bagi memperoleh sokongan penduduk kampung dengan cara memberi 'Derma Unta'. Berdasarkan analisis wacana kritis yang dilakukan, babak ini dipercayai sebagai cemuhan terhadap sikap sebahagian daripada ahli politik yang tidak amanah dan mereka digelar sebagai orang-orang yang 'bangsat'. Berdasarkan analisis, Rajah 1 'Elamat Bangsat' pengarah menunjukkan secara hipotetikal sekiranya seseorang buta huruf dan tidak pandai mengeja akan menyebabkan seseorang yang buta budi bahasa (menggunakan kata-kata makian) seperti bangsat dan menggunakan bahasa kesat serta negatif seolah-oleh tiada jati diri kerana slogan yang diutamakan di negara ini ialah 'Bahasa Jiwa Bangsa'. Isu bahasa akan dibincangkan berdasarkan ketiga- tiga Rajah yang menunjukkan placard yang dipegang oleh penduduk kampung. Pengarah seperti memberikan 'peluang kedua' kepada penduduk kampung bagi membetulkan kelemahan serta kesalahan ejaan atau bahasa mereka seperti babak seterusnya dalam Rajah 2.

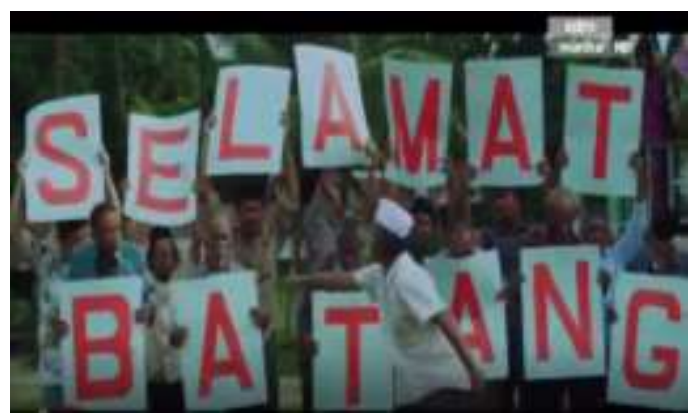

Rajah 2: 'Selamat Batang'

Rajah 2 menunjukkan penduduk kampung menyusun semula ejaan perkataan 'Selamat Datang' kepada 'Selamat Batang' seperti yang diajarkan oleh Khamis. Kesalahan ejaan ini adalah kesalahan ejaan yang kedua dan menunjukkan kelemahan penguasaan ejaan dalam Bahasa Melayu oleh bangsa Melayu itu sendiri. Inilah kebijaksanaan pengarah dalam membina sebuah satira terhadap isu kedaulatan Bahasa Melayu di negara ini. Satira dalam babak ini merupakan isu bahasa yang masih belum tuntas kerana kesalahan ejaan masih tetap berlaku sedangkan kesalahan ejaan dan kepandaian mengeja adalah asas kecelikan serta literasi bagi membaca dan menulis yang ingin diterapkan oleh pemerintah ke atas setiap warga Malaysia. Babak ini bagaimanapun menunjukkan kegagalan terhadap Dasar Bahasa. Pada lapisan lain, babak ini merupakan tempelakan terhadap situasi semasa berkaitan budaya bahasa WeChat yang telah merosakkan bahasa akibat daripada kesalahan ejaan yang tidak dapat dikawal. 


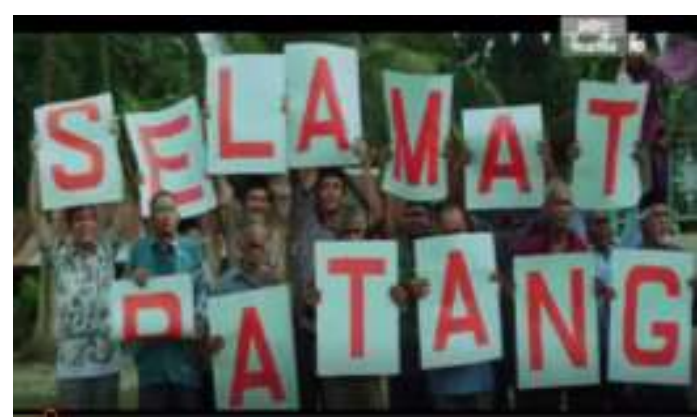

Rajah 3: 'Selamat Datang'

Rajah 3 merupakan kata aluan 'Selamat Datang' yang telah dieja dengan betul hanya setelah huruf ' $B$ ' dilipat agar kelihatan sebagai ' $D$ '. Ini merupakan tindakan spontan penduduk kampung bagi menutup kesalahan ejaan yang terus berlaku. Tidak dinafikan bahawa bunyi 'batang' dan 'datang' amatlah dekat tetapi ia merupakan kesalahan yang besar kerana keduadua perkataan tersebut membawa maksud yang berbeza. Ketiga-tiga Rajah merupakan babak yang dirancang bagi menghiburkan penonton. Walau bagaimanapun ia mempunyai lapisan makna yang lebih mendalam tetapi mungkin difahami atau tidak difahami pengertiannya oleh audiens. Babak ini kelihatan seperti permainan Roda Impian yang merupakan sebuah program teka kata yang diadaptasi daripada rancangan popular di seluruh dunia, Wheel of Fortune.

Babak pada Rajah 1, 2 dan 3 menunjukkan pengarah mensatirakan orang-orang dewasa bangsa Melayu yang tidak pandai mengeja, tidak berbudi bahasa dan orang kampung dimanipulasikan oleh pengarah seperti 'haiwan ternakan' yang hanya menurut arahan semata-mata. Babak ini mensatirakan tradisi menyambut 'Tamu Agung' dan agak melucukan apabila sambutan dilakukan oleh orang dewasa yang 'diperbodohkan'. Babak ini sarat dengan satira kerana ia bukan sahaja menyindir isu bahasa, 'kebodohan' penduduk kampung tetapi juga kecaman terhadap politikus. Kebijaksanaan pengarah dalam mensatirakan beberapa isu dapat dilihat daripada segi bentuk persembahan semasa sambutan VIP tersebut.

ii. Institusi Perbomohan

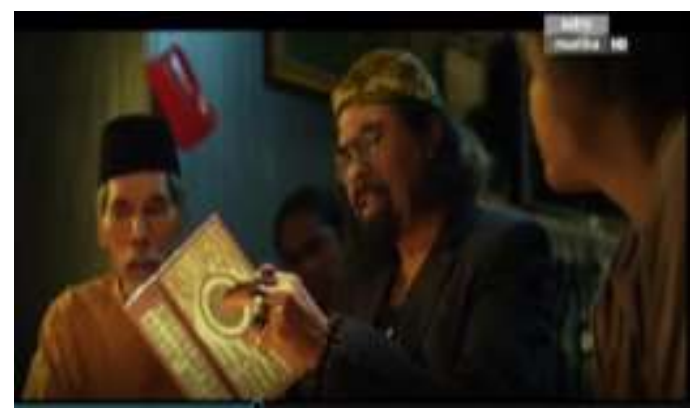

Rajah 4: Tok Bomoh merujuk 'Ensiklopedia Hantu Melayu'

Rajah 4 merupakan babak Tok bomoh merujuk 'Ensiklopedia Hantu Melayu' untuk mengenal pasti jenis makhluk halus yang mengganggu penduduk kampung. Penduduk kampung menemui bomoh untuk mendapatkan bantuan bagi menyelesaikan masalah berkaitan 'hantu' yang membelenggu kehidupan mereka. Beberapa kejadian pelik yang terjadi di kampung tersebut telah dikaitkan dengan kehadiran 'hantu' yang dikatakan tinggal di dalam rumah lama yang diangkat keluar dari dalam hutan tersebut. Dalam babak ini, bomoh telah mengesahkan apa yang difikirkan oleh orang kampung adalah 'hantu' berupa 'Orang Minyak'. 
Bagi mengesahkan dakwaan orang kampung, si bomoh telah merujuk kepada ciri-ciri yang dimaklumkan oleh Wan dan orang kampung dengan membandingkan maklumat yang terdapat dalam 'Ensiklopedia Hantu Melayu' seperti di bawah:

Bomoh: Dan kamu anak muda, kamu nampak apa? Jangan takut, jangan bimbang.... Aku datang sini nak bantu kau

Wan: Saya pun ada nampak lembaga hitam tu....

Bomoh: Hitam.... Hitam (merujuk Ensiklopedia Hantu Melayu)

Bomoh: Kepala lembaga tu melekat pada badan dia? Hmm (respon wan) ada dia terbang melayang-layang?

Wan: Dia jejak kat tanah

Bomoh: Jadi dia itam, jejak kat tanah, badan dia berminyak? (Merujuk Ensiklopedia Hantu Melayu)

Wan: Nampak sikit-sikit jer, itam dan berkilat

(Bomoh membaca jampi)

Bomoh: Jadilah jadi...jadilah jadi.... jadilah jadi.... jadilah jadiiiiii...... Pada firasat aku, lembaga ini ialah setan. Setan bersalut minyak hitam

Cina: 'Orang Minyak' (lye.... 'Orang Minyak' ke tok?)

Bomoh: Kalau firasat macam tu, kau percaya. Itulah yang kau percaya!!

(LHD, 00:45:58)

Menurut Shuhairimi (2006), bomoh juga dikenali sebagai tabib kampung yang mengubati orang sakit dengan menggunakan kaedah tradisional seperti menggunakan jampi dan sebagainya. Lazimnya, seorang bomoh tidak menggunakan 'kitab' atau merujuk kepada ensiklopedia seperti yang dipertontonkan dalam filem LHD. Penggunaan ensiklopedia dalam babak ini merupakan sesuatu yang mengandungi unsur humor terhadap institusi perbomohan. Babak ini mengetengahkan hubungan intertekstual antara 'kitab' si bomoh dengan 'kitab' yang telah ditulis oleh William Skeat (1900) bertajuk Malay Magic: Being an Introduction to the Folklore and Popular Religion of the Malay Peninsula yang menceritakan isu berkaitan sifat dan penciptaan fenomena, asal usul alam semesta, hubungan dengan dunia ghaib, semangat, syaitan dan hantu yang menjadi rujukan banyak pihak bagi memahami isuisu mistik berkaitan bangsa Melayu. Buku tersebut telah diterbitkan semula dalam bentuk buku elektronik pada tahun 2015 dan boleh dibaca secara dalam talian oleh semua orang. Babak ini merupakan sindiran terhadap falsafah metafizik yang mendominasi alam dan akal budi masyarakat Melayu.

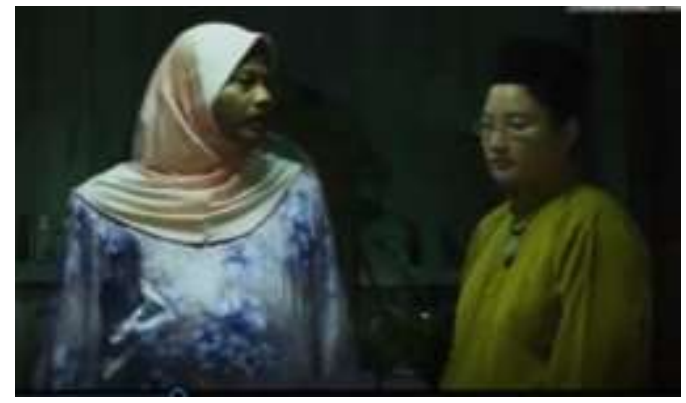

Rajah 5: Sepasang suami isteri bertukar persalinan bagi mengelirukan 'Orang Minyak'. 
Rajah 5 merupakan sepasang suami isteri yang bertukar persalinan bagi mengelirukan 'Orang Minyak' supaya tidak merogol kaum wanita di kampung tersebut. Dalam babak ini, kaum lelaki memakai pakaian wanita manakala kaum wanita memakai pakaian lelaki lengkap bersongkok dan bertudung. Kaum lelaki yang berpakaian wanita kemudiannya keluar rumah bagi menjaga keselamatan kampung dan wanita yang berpakaian lelaki tinggal di rumah menjaga anak-anak. Idea menukar persalinan bagi mengelakkan diperkosa 'Orang Minyak' merupakan sebuah justifikasi logik yang lemah namun diterima dan dilaksanakan oleh orang kampung kerana mereka terlalu mempercayai kata-kata bomoh tanpa mempertimbangkannya terlebih dahulu. Selain itu, situasi ini merupakan pengalihan wacana biasa terhadap transgender daripada sesuatu yang menyalahi norma kepada sesuatu yang dihalalkan oleh bomoh. Wacana dominan berkaitan transgender di Malaysia menyatakan perbuatan memakai pakaian lawan jantina adalah salah dan dilarang. Isu transgender merupakan isu sosial masyarakat yang hangat diperkatakan sejak beberapa tahun mutakhir ini. Isu transgender disatirakan dengan cara yang santai dan mencuit hati namun tersulam makna-makna tersirat di dalamnya. Dalam filem LHD, penampilan hanyalah perlambangan kepada gender dan merupakan lapisan luar dan tidak memberi impak terhadap fungsi lelaki dan wanita seperti yang telah menjadi kebiasaan selama ini.

\section{Satira Politik}

i. Derma Unta

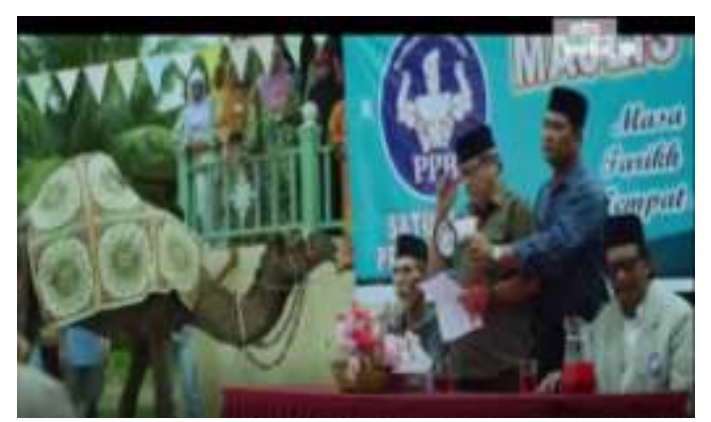

Rajah 6: Encik Juta Seri berucap sebelum menyerahkan unta

Rajah 6 menunjukkan Encik Juta Seri sedang memberi ucapan semasa majlis 'Derma Unta' kepada Masjid Kubah Baru di kampung mereka. Menerusi babak dalam bingkai ini, Encik Juta Seri dipaparkan sebagai ahli politik mewakili Persatuan Pemuda Bersatu (PPB) dan program 'Derma Unta' merupakan projek PPB bersama penduduk kampung. Sumbangan yang diberikan berupa seekor unta untuk dikorbankan semasa Hari Raya Aidiladha yang disambut pada 10 Zulhijjah manakala ibadah korban pula dilaksanakan pada 10, 11, 12 dan 13 Zulhijjah dalam takwim Hijriyyah. Ibadah korban memberi makna penting dalam kehidupan umat Islam kerana ia melambangkan keimanan dan ketakwaan umat Islam kepada Allah SWT. Di Malaysia, sudah menjadi kelaziman untuk mengorbankan haiwan ternakan seperti lembu, kambing atau kerbau. Namun Encik Juta Seri mendermakan unta sebagai korban dan ia bukanlah suatu kebiasaan kerana unta merupakan haiwan ternakan di kawasan gurun atau padang pasir yang panas seperti di Semenanjung Arab. Kejanggalan ini hampir saja menutup implikasi kos membeli dan mengimport haiwan ini yang sudah 'ditanggung' oleh ahli politik yang Islami, atau tepatnya, 'keAraban' ini. 


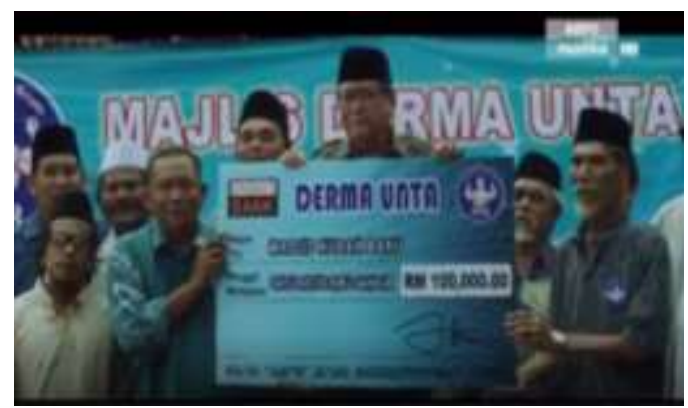

Rajah 7: Encik Juta Seri menyerahkan replika cek 'Derma Unta' kepada Tok Ketua

Rajah 7 menunjukkan Encik Juta Seri menyerahkan replika cek 'Derma Unta' bernilai RM100,000.00 kepada Tok Ketua dan penduduk kampung. Beberapa hari selepas berlangsungnya majlis, unta yang didermakan telah hilang dan situasi ini menimbulkan kerunsingan Tok Ketua yang terpaksa memberitahu anak-anak buahnya nilai sebenar unta itu seperti dialog di bawah:

Penduduk kampung: Unta yang hilang tu berapa harganya Tok?

Tok Ketua: Enam.

Penduduk kampung: Eh...tapi cek besar hari tu dia tulis RM 100,000.00 kan tok

Tok Ketua: Ye la... RM 94,000.00 tu untuk perbelanjaan sampingan, yang tu kau tak perlu tau la.

(LHD, 00:57:24)

Melalui dialog di atas, didapati bahawa harga unta yang didermakan oleh Encik Juta Seri dari Persatuan Pemuda Bersatu (PPB) ialah RM 6,000.00 dan lebihan RM 94,000.00 merupakan kos sampingan yang tidak dinyatakan kegunaannya oleh Tok Ketua. Didapati Tok Ketua tidak telus dengan penduduk kampung kerana merahsiakan maklumat berkaitan perbelanjaan sampingan yang dimaksudkan. Babak ini merupakan sebuah satira politik yang merupakan kritikan keras terhadap senario semasa politik Malaysia berkaitan ketirisan dalam pengurusan kewangan, salah guna kuasa dan rasuah oleh individu tertentu. Rajah 6 dan Rajah 7 merupakan kritikan berkaitan isu semasa politik Malaysia seperti isu derma RM2.6 juta, $1 M D B$ dan salah guna kuasa individu tertentu. Jawatan yang disandang membuka ruang kepada seseorang untuk memberi, menerima dan melakukan salah laku dalam pengurusan kewangan. Analisis mendapati bahawa bingkai-bingkai ini merupakan satira terhadap isu rasuah, penyalahgunaan kuasa dan ketirisan pengurusan kewangan. Mereka berpandangan bahawa institusi seperti Suruhanjaya Pencegahan Rasuah Malaysia (SPRM) juga tidak telus kerana dipengaruhi oleh kuasa-kuasa tertentu dan rasuah dianggap suatu kebiasaan dan disebut sebagai 'hadiah' dan 'duit kopi' bagi 'menghalalkan' perbuatan menerima hadiah atau sumbangan. Babak-babak dalam bingkai di atas merupakan satira terhadap salah laku masyarakat dalam arena politik khasnya.

\section{RUMUSAN DAN PERBINCANGAN}

Dapat dirumuskan bahawa satira sosiobudaya dan politik lazimnya dikonstruksi oleh mereka yang peka sebagai 'pemerhati' isu dan perspektif yang terdapat dalam sesebuah masyarakat. Maka tidak menghairankan jika dalam filem LHD, watak orang kampung dikonstruksikan sebagai sekumpulan orang yang naif dan pendek akalnya. Ketajaman akal dalam membaca hal yang tersurat tidaklah begitu diutamakan oleh golongan intelektual dan pewacana kritis 
kerana hal yang lebih penting dan strategik ialah keupayaan menemukan makna atau memberikan pencerahan terhadap sesuatu isu atau perspektif secara dekonstruktif dalam mengangkat agenda dan kepentingan peribumi (Faiznur Farhana et al., 2016). Inilah juga yang disarankan oleh Derrida menerusi teori dan analisis dekonstruksi yang berfungsi sepenuhnya bagi tujuan membongkar dan membincangkan makna-makna yang tersulam dan terkonstruksi dalam lingkungan sosiobudaya dan politik.

Justeru, pengarah LHD memilih untuk mewacanakan persoalan bahasa dan metafizika dalam masyarakat Melayu di negara yang serba moden ini menerusi satira sosiobudaya yang penuh persendaan dan lelucon. Kepercayaan orang Melayu terhadap kemampuan bomoh dalam menyelesaikan persoalan metafizika dalam masyarakat Melayu. Pengarah LHD menggambarkan bomoh sebagai tempat rujukan, mempunyai ilmu kebatinan yang tinggi dan boleh membantu menyelesaikan masalah orang kampung yang berkaitan alam ghaib, mistik atau metafizik. Filem ini mengangkat isu institusi perbomohan sebagai sesuatu yang penting dalam kehidupan dan sosiobudaya bangsa Melayu kerana institusi perbomohan amat sinonim dengan bangsa Melayu. Institusi perbomohan disatirakan dalam kedua-dua filem kerana kepercayaan melampau masyarakat Melayu terhadap kemampuan bomoh dilihat sebagai suatu isu yang sangat dekat dengan kepercayaan orang Melayu. Antara isu yang menjadi tular berkaitan institusi perbomohan di Malaysia ialah isu Raja Bomoh Sedunia (Ibrahim Mat Zin) melalui ritual yang dilakukan di Lapangan Terbang Antarabangsa (KLIA) bagi mengesan pesawat MH370 yang hilang pada tahun 2014. Beliau dan pengikutnya melaksanakan ritual tersebut menggunakan kelapa, teropong buluh, tongkat, perangkap ikan dan permaidani bagi mengesan pesawat MH370 yang hilang. Pada April 2017, Raja Bomoh Sedunia akhirnya mengaku berbohong dan memohon maaf kepada semua masyarakat beragama Islam dan bukan Islam di negara ini serta semua pihak di seluruh dunia berhubung tindakannya melakukan ritual yang salah dan bertentangan dengan ajaran Islam. Faktanya, pesawat MH370 tidak dapat dikesan dan kehilangannya terus menjadi misteri sehingga hari ini.

Terdahulu, Malaysia telah digemparkan dengan kes pembunuhan kejam terhadap seorang ahli politik, Datuk Mazlan Idris pada tahun 1993 yang telah mendapatkan perkhidmatan bomoh bagi meningkatkan kerjaya politiknya. Misteri kehilangan beliau terbongkar apabila ditemui mati dibunuh dan mayatnya dipotong kepada 18 bahagian serta ditanam dalam lubang sedalam 1.8 meter dengan permukaannya disimen. Tangkapan serta perbicaraan dilaksanakan terhadap pasangan bomoh Maznah Ismail atau Mona Fandey, 46, dan suaminya, Mohd Affandi Abdul Rahman, 45, serta pembantu mereka, Juraimi Husin, 32. Mereka didapati terbabit dan disabitkan kesalahan membunuh Mazlan pada 9 Februari tahun 1995 di Mahkamah Tinggi Temerloh dan dijatuhi hukuman gantung sampai mati. Pada tahun 2006, sebuah filem arahan Dain Iskandar Said yang bertajuk Dukun yang diinspirasikan daripada kisah Mona Fandey telah diterbitkan namun ia tidak ditayangkan ketika itu kerana tidak sesuai untuk tayangan umum. Filem Dukun telah ditayangkan kepada umum pada 5 April 2018 iaitu setelah 12 tahun filem tersebut 'disimpan' (baca digantung dari tontonan awam). Kedua-dua kes ini merupakan contoh besarnya pengaruh metafizik bomoh dan ketaksuban masyarakat terhadap institusi perbomohan.

Di sudut lain, kebergantungan terhadap 'kepandaian' si bomoh ini merupakan sindiran terhadap golongan yang malas membaca atau mencari ilmu pengetahuan dalam kalangan masyarakat Melayu amnya. Adalah jelas walaupun si bomoh tidak menggunakan kaedah saintifik bagi mengesahkan kehadiran 'Orang Minyak', beliau masih perlu membuat kajian dan rujukan kepada 'kitab' atau ensiklopedia dalam topik 'hantu' dan tidak membuat keputusan secara 'membuta tuli'. Secara ironis pengarah menyedarkan masyarakat supaya 
tidak mudah dimanipulasi dan perlu berfikir secara logik dan boleh diterima akal serta membuat rujukan terhadap sesuatu perkara yang mereka tidak pasti. Secara makro, ia merupakan satira terhadap rakyat Malaysia yang kurang membaca. Menurut laporan statistik oleh Perpustakaan Negara Malaysia, pada tahun 2017 purata pembacaan buku di Malaysia adalah antara 15 hingga 20 buah buku bagi tempoh setahun dan ia merupakan bilangan yang rendah (www.pnm.gov.my).

Dalam masa yang sama, isu semasa berkaitan penjualan barang tiruan, kemasukan pendatang asing tanpa izin dan keselamatan dalam negeri yang menandakan kepincangan penguatkuasaan membuat keputusan dan dasar kepimpinan politik negara. Pun begitu, satira politik dalam filem ini dibayangi oleh babak 'Derma Unta' yang dilihat sebagai kritikan pengarah Seng Tat terhadap masalah korupsi dalam kalangan para pemimpin politik yang sentiasa dahagakan kuasa politik. Satira politik dalam filem LHD ini boleh dibahagikan kepada dua iaitu politik di peringkat kampung dan politik negara yang melibatkan pilihanraya. Pengarah memainkan isu-isu berkaitan kuasa dalam politik, peranan individu berautoriti seperti ketua kampung serta agamawan, sistem feudal dan pengurusan kewangan telah disatirakan dalam filem LHD. Berdasarkan isu-isu yang diketengahkan, filem LHD telah mensatirakan isu-isu semasa yang menjadi tular dan menimbulkan kemarahan rakyat ketika itu seperti isu 1MDB, sumbangan RM2.6 bilion dan sistem pemerintahan yang menzalimi rakyat telah ditonjolkan. Secara keseluruhannya, filem ini mengetengahkan isu sosiobudaya dan politik yang hampir sama di negara ini namun ia disandarkan kepada konteks yang berbeza dan setiap topik dikupas dari perspektif yang berbeza secara sederhana tanpa menyinggung mana-mana pihak secara langsung. Justeru, satira digunakan bagi menyampaikan kritikan terhadap orang Melayu kerana sifat orang Melayu yang sangat sensitif dan sukar untuk menerima kritikan secara terus.

\section{Satira Akal Budi Melayu}

Dengan wujudnya karya-karya yang berbentuk satira telah melahirkan masyarakat yang celik membaca satira. Secara tidak langsung masyarakat dididik agar berfikir secara kritis bagi memahami makna-makna yang tersirat di sebalik sesebuah karya berbentuk satira. Hal ini dapat dilihat berdasarkan maklum balas informan terhadap makna lain yang terdapat dalam filem LHD yang telah dikaji. Selain itu, karya-karya satira juga telah melahirkan masyarakat yang lebih sensitif terhadap isu-isu semasa khasnya yang mempunyai kaitan dengan sosiobudaya dan politik orang Melayu di Malaysia. Masyarakat masa kini telah terbiasa dengan kritikan berbentuk satira dan jika diperhatikan di media sosial, rakyat marhaen telah mula bersatira mengenai isu-isu tular yang melibatkan individu berprofil tinggi atau tokoh masyarakat. Setiap lapisan masyarakat telah meninggalkan komen atau respon berbentuk satira melalui penulisan, gambar dan bahan audio video di media sosial. Situasi ini jelas menunjukkan bahawa masyarakat kini lebih sensitif terhadap isu-isu semasa yang berlaku di sekeliling mereka dan melahirkan rakyat yang lebih bertanggungjawab terhadap negara. Apa yang sedang berlaku ialah penggembelingan satira sebagai suatu karakteristik akal budi Melayu moden menerusi kemajuan medium filem, khususnya pemerkasaan naratif dan genre satira dalam industri filem nasional. Dengan bantuan kecanggihan teknologi komunikasi massa seperti filem, penyuburan satira oleh masyarakat di media baharu dilihat berkembang dengan pantas. Satira yang disampaikan melalui medium komunikasi massa amnya dapat memberi impak yang besar dalam pembinaan persepsi masyarakat kerana ia mudah diakses dan bersifat 'bebas' dan jika berlaku secara berterusan akan mempengaruhi sesebuah 
tindakan atau keputusan seseorang hasil daripada pembinaan persepsi yang utuh. Muammar Ghadaffi (2019, hlm.69) menegaskan bahawa "falsafah hidup dan akal budi bangsa perlu dipertingkatkan dan dikemaskini dari semasa ke semasa selaras dengan wawasan negara yang didukung oleh kerajaan".

Akal budi Melayu Islam mengajar bahawa sebarang bentuk kesalahan wajar ditegur dan diperbetulkan walaupun seseorang itu pembesar atau pemerintah. Muammar (2019, hlm.69) menegaskan bahawa "falsafah hidup dan akal budi bangsa perlu dipertingkatkan dan dikemaskini dari semasa ke semasa selaras dengan wawasan negara yang didukung oleh kerajaan". Kaedah yang ditonjolkan dalam LHD menunjukkan masyarakat atau khalayak Melayu lebih suka sama ada mentertawakan 'kesalahan' atau memperbetulkan 'kesalahan' itu secara berlapik. la diolah semula dalam bentuk naratif atau cerita dengan gaya retorik bahasa yang melanggar hukum dalam prinsip pertuturan untuk mewujudkan kesan humor dan parodi yang bersifat halus dan berlapik serta tidak 'menyakitkan'. Senario ini bertepatan dengan harapan kerajaan yang mengalu-alukan kritikan serta teguran daripada rakyat terhadap kepimpinan dalam era 'Malaysia Baharu'. Berdasarkan analisis dan pandangan daripada informan didapati bahawa mereka memahami setiap isu yang disatirakan dan ia telah membina satu persepsi terhadap pelaku berdasarkan isu yang disatirakan. Hasil kutipan yang tinggi dan pengiktirafan terhadap sesebuah filem menjadi kayu ukur terhadap penerimaan dan kefahaman penonton berkaitan isu yang disatirakan. Satira adalah lambang kepada ketinggian akal budi Melayu dan pengkarya yang menggunakan satira dalam karya mereka mempunyai masa hadapan yang cerah dalam industri kreatif hari ini. Kebangkitan genre komidi satira merupakan petanda kepada pembugaran satira sebagai medium komunikasi yang unggul kerana satira memerlukan ketajaman akal fikiran dan kebijaksanaan yang tinggi. Naratif satira bersesuaian dengan iklim sosiobudaya dan politik Malaysia hari ini terutama dalam kalangan generasi millennial.

\section{KESIMPULAN}

Sebagai kesimpulan, satira telah lama digunakan oleh rumpun Melayu di Nusantara, terutamanya Malaysia. Akal tradisi Melayu mengajar kita agar menegur dalam senyum, mengata dalam ketawa dan mengajar dalam nasihat. Kini, media massa banyak menggunakan kerangka satira sebagai cara untuk membincangkan isu berkaitan sosiobudaya dan politik di Malaysia. Isu-isu berkaitan kepercayaan dan sosiobudaya dan politik orang Melayu merupakan asas kepada penghasilan karya satira yang disampaikan melalui filem LHD dan secara keseluruhannya dapat dinyatakan bahawa sebuah satira dibina berdasarkan kejadian semasa yang tidak seharusnya berlaku dalam masyarakat. Fenomena semasa ini telah menyumbang kepada terbinanya sesebuah satira dan ia dilakukan sebagai kritikan terhadap perkara tersebut. Komunikasi massa menggunakan gaya bahasa satira perlu difahami dengan baik oleh masyarakat kerana ia merupakan medium yang polular dan menjadi fenomena pada masa kini bagi menyampaikan kritikan dan protes terhadap sesuatu situasi. Kini, satira semakin diterima umum sebagai satu genre sastera yang penting dan mempunyai peranan yang tersendiri sebagai fungsi akal budi dalam dunia yang serba berubah. Komunikasi satira perlu diberi perhatian kerana ia memperlihatkan kesuburan dalam intelektual yang tinggi dan melambangkan ketajaman akal budi Melayu. Filem mempunyai tiga peranan utama iaitu memaklumkan, mempengaruhi dan menghiburkan. Sesebuah filem mempunyai kuasa untuk mempengaruhi emosi, minda dan membentuk kehidupan penonton. Sebuah satira yang baik mampu menjalankan peranan ini dengan cemerlang. Menyampaikan satira menggunakan media elektronik iaitu filem merupakan satu tindakan yang berani dan menuntut kepada 
kreativiti yang tinggi kerana penggunaan filem sebagai medium penyampai satira kepada audiens memberi impak terhadap pemahaman dan tindakan audiens.

\section{BIODATA}

Badrul Redzuan Abu Hassan ialah pensyarah kanan di Pusat Kajian Media dan Komunikasi, Fakulti Sains Sosial dan Kemanusiaan, Universiti Kebangsaan Malaysia. Bidang pengkhususan beliau ialah Kajian Media dan Budaya. Emel: brah@ukm.edu.my

Nur Hafizoh Idris ialah graduan ijazah Sarjana Sains Sosial (Pengurusan Komunikasi) di Pusat Kajian Media dan Komunikasi, Fakulti Sains Sosial dan Kemanusiaan, Universiti Kebangsaan Malaysia.Emel: fizoidris@yahoo.com 


\section{RUJUKAN}

A. Aziz Deraman. (2000). Tamadun Melayu dan pembinaan bangsa Malaysia (edisi baharu). Kuala Lumpur: Dewan Bahasa Pustaka.

Abdul Rahman Embong. (1999). Melayu baru dan wacana tentang pemodenan masyarakat Melayu (Siri kertas kerja sosiologi dan antropologi no. 2). Bangi: Universiti kebangsaan Malaysia.

Asmah Haji Omar. (1986). Bahasa dan alam pemikiran Melayu. Kuala Lumpur: Dewan Bahasa dan Pustaka.

Badrul Redzuan Abu Hassan. (2018). Analisis wacana. DIm. Normah Mustaffa, Ali Salman, \& Badrul Redzuan Abu Hassan (pnyt.), Reka bentuk penyelidikan komunikasi (HIm. 111123). Kuala Terengganu: Penerbit Universiti Malaysia Terengganu.

Faiznur Farhana Jaafar, Badrul Redzuan Abu Hassan, \& Roslina Abdul Latif. (2016). Mengkonstruksi ke-Sabahan: Analisis kritis sinematik terhadap wacana kedaerahan. Jurnal Komunikasi: Malaysian Journal of Communication, 32(2), 165-185.

Faizul Nizar Anuar, Fauziah Ahmad, \& Sabariah Mohamed Salleh. (2018). Imeme sebagai seloka persendaan dan parodi: Impak dimensi sosiobudaya. Jurnal Komunikasi: Malaysian Journal of Communication, 34(1), 75-96.

Fatimah Busu. (1992). Elements of satire in the modern Malay and African novel. Kuala Lumpur: Dewan Bahasa dan Pustaka.

Griffin, D. (2015). Satire: A critical reintroduction. US: University Press of Kentucky.

Hani Salwah Yaakup. (2013). Membaca satira dalam humor karya penulis muda. Tunas Cipta. Selangor: Universiti Putra Malaysia.

Koko Keumala Nurhidayat. (2016). Analisis gaya bahasa satira dan pesan pada rubrik lincak surat kabar harian Solopos. Surakarta: Universitas Muhammadiyah Surakarta.

Laporan Perpustakaan Negara Malaysia 2017. Diperoleh pada, 10 April 2019, dari http//: www.pnm.gov.my

Liew Seng Tat. (2014). Lelaki harapan dunia. Everything Film.

Muammar Ghaddafi Hanafiah. (2019). Isu membidaahkan amalan masyarakat Melayu: Analisis wacana media kritis. Jurnal Komunikasi: Malaysian Journal of Communication. 35(2), 68-86.

Noor Hasnoor Mohamad Nor, Eizah Mat Hussain, \& Ahmad Ramizu Abdullah. (2019). Kesopanan dalam komunikasi menerusi filem animasi kanak-kanak tempatan. Jurnal Komunikasi: Malaysian Journal of Communication, 35(4), 368-385.

Raja Nurafiqah Raja Zulkifli, Noor Sulastry Yurni Ahmad, Mohd Azizuddin Mohd Sani, \& Haslina Muhamad. (2018). Impak satira politik terhadap Internet trolling di Malaysia. Jurnal Komunikasi: Malaysian Journal of Communication, 34(2), 223-242.

Shuhairimi Abdullah. (2006). Institusi bomoh dalam masyarakat melayu menurut perspektif Islam. Jurnal Pembangunan Sosial, 5(2), 181-203.

Whitebourd Journal. (t. th.). Majalah humor Amerika kembali dengan rona segar. Diperoleh pada 23 Mei 2019, di http://MajalahMad/Gilagila/hiburan/satira

Yusri Abdul Malek dan Noor Jaafar. (2005, 17 Mei). Bangsat sarat sindiran tajam. Harian Metro. 